\title{
Função ovariana de novilhas Nelore alimentadas com dieta suplementada com gordura protegida ruminal
}

\author{
Monique Mendes Guardieiro(1), Michele Ricieri Bastos(2), Gerson Barreto Mourão(1), \\ Luiz Henrique Dantas Carrijo ${ }^{(3)}$, Eduardo de Oliveira Melo(4), Rodolfo Rumpf ${ }^{(4)}$ e Roberto Sartori ${ }^{(1)}$
}

\begin{abstract}
(1)Universidade de São Paulo, Escola Superior de Agricultura Luiz de Queiroz, Caixa Postal 09, CEP $13418-900$ Piracicaba, SP. E-mail: moniqueguardieiro@yahoo.com.br, gbmourao@esalq.usp.br, sartori@esalq.usp.br (2)Universidade Estadual Paulista, Faculdade de Medicina Veterinária e Zootecnia, Distrito de Rubião Júnior, s/no, CEP 18618-000 Botucatu, SP. E-mail: michelerbastos@hotmail.com ${ }^{(3)}$ Integral Nutrição Animal, Rodovia GO-070, Km 8,3, CEP 74477-228 Goiânia, GO. E-mail: carrijo@integralprodubon.com.br (4)Embrapa Recursos Genéticos e Biotecnologia, Caixa Postal 02372, CEP 70770-900 Brasília, DF. E-mail: eom@cenargen.embrapa.br, rodolfo@cenargen.embrapa.br
\end{abstract}

Resumo - O objetivo deste trabalho foi avaliar o efeito da suplementação alimentar com gordura protegida ruminal sobre as estruturas ovarianas e sobre a concentração sérica de progesterona, em novilhas Nelore mantidas em pasto. Quarenta novilhas foram divididas em dois grupos: um suplementado com gordura protegida Megalac-E (G); e outro sem suplementação de gordura (C). O grupos foram avaliados em delineamento "crossover". Utilizaram-se dietas isoenergéticas e isoproteicas. Após 15 dias de suplementação, os animais foram submetidos a um protocolo hormonal, para avaliação da influência da suplementação com gordura no metabolismo da progesterona. Para isto, em um dia aleatório do ciclo (D0), inseriu-se um implante intravaginal de liberação de progesterona (CIDR), e aplicou-se prostaglandina F2 $\alpha$ (PGF2 $\alpha$, i.m.). No D7, o implante foi retirado, e outra aplicação de PGF2 $\alpha$ foi realizada. No D18, foi feita uma nova aplicação de PGF2 $\alpha$ e, então, foram observados diariamente os exames ultrassonográficos ovarianos e a ocorrência de estro. Para o ensaio com progesterona, colheu-se sangue 4 dias após a inserção do implante e, novamente, 7 e 14 dias após a ovulação. A concentração de progesterona sérica no D4 foi maior no grupo G. Não houve diferença nas concentrações séricas de progesterona 7 e 14 dias após a ovulação, nem no diâmetro do folículo ovulatório, nem no volume luteal. A suplementação com Megalac-E altera o metabolismo de progesterona, mas não altera a função ovariana em novilhas zebuínas em pasto.

Termos para indexação: Bos indicus, ácidos graxos, corpo lúteo, folículo, progesterona.

\section{Ovarian function of Nelore heifers fed a diet supplemented with rumen-protected fat}

\begin{abstract}
The objective of this work was to evaluate the effect of rumen-protected fat supplementation on ovarian structures and on serum progesterone concentration in Nelore heifers kept in pasture. Forty heifers were divided into two groups: one supplemented with rumen-protected fat Megalac-E (F); and another without fat supplement (C). The groups were evaluated in a crossover design. The diets were isocaloric and isoproteic. After 15 days of supplementation, the animals were submitted to a hormonal protocol to evaluate the influence of fat supplementation on progesterone metabolism. For this, on a random day of the cycle (D0), the heifers received an intravaginal progesterone-releasing device (CIDR) and an injection of prostaglandin F2 $\alpha$ (PGF2 $\alpha$, im). On D7, CIDR was removed and another injection of PGF2 $\alpha$ was performed. On D18, a new treatment with PGF2 $\alpha$ was done and, then, daily observations of estrus and ovarian ultrasound exams were carried out. For progesterone assay, blood samples were collected 4 days after CIDR insertion, and 7 and 14 days following ovulation. Serum progesterone concentration on D4 was higher for Group F. There was no difference between groups for serum progesterone concentration at 7 or 14 days following ovulation, neither in the ovulatory follicle, nor in the corpus luteum volume. Supplementation with Megalac-E alters progesterone metabolism, but does not affect ovarian function in zebu heifers kept in pasture.
\end{abstract}

Index terms: Bos indicus, fatty acids, corpus luteum, follicle, progesterone.

\section{Introdução}

A suplementação com gordura é uma prática comum para aumentar a densidade energética de dietas para animais, principalmente para gado de leite. Entretanto, além de fornecer calorias, a gordura possui efeito direto na reprodução (Funston, 2004; Raes et al., 2004), com elevação da fertilidade em muitas situações. Há relatos de efeito dos ácidos graxos sobre: o número e o tamanho de folículos ovarianos (Lucy et al., 1991; Robinson

Pesq. agropec. bras., Brasília, v.45, n.4, p.408-414, abr. 2010 
et al., 2002; Bilby et al., 2006); o tamanho do corpo lúteo (CL) (Raes et al., 2004; Bilby et al., 2006); e a qualidade ovocitária (Kim et al., 2001; Zeron et al., 2002). Além disso, outros autores também observaram que dietas que continham ácidos graxos influenciaram a qualidade embrionária (Kojima et al., 1997; Childs et al., 2008a; Cerri et al., 2009) e a concentração circulante de prostaglandina e hormônios esteroides (Ryan et al., 1992; Petit et al., 2002; Childs et al., 2008b). Neste último caso, não estão bem definidas as causas da associação observada entre a suplementação com lipídeos e as maiores concentrações circulantes de hormônios esteroides. Conjectura-se que elas ocorram por meio da ação de ácidos graxos poli-insaturados (AGP), que aumentam a pulsatilidade de hormônio luteinizante (LH) (Hightshoe et al., 1991), com um consequente aumento no tamanho do folículo pré-ovulatório e no subsequente CL (Raes et al., 2004), ou pela diminuição do metabolismo hepático desses hormônios (Hawkins et al., 1995). Outras possibilidades seriam as de que essa associação ocorresse pelo aumento das concentrações circulantes de colesterol, precursor da síntese de esteroides (Thomas et al., 1997), ou mesmo pela alteração na síntese de prostaglandina F2 $\alpha$ (PGF2 $\alpha$ ) (Petit \& Twagiramungu, 2006; Childs et al., 2008b).

A teoria da diminuição do metabolismo dos esteroides é atualmente uma das mais discutidas para explicar as maiores concentrações séricas de esteroides resultantes da suplementação lipídica. Hawkins et al. (1995) avaliaram o mecanismo pelo qual a inclusão de gordura na dieta aumenta a concentração de progesterona circulante, por meio do fornecimento, com início 100 dias antes do parto, de sais de cálcio de ácidos graxos de cadeia longa. A concentração de progesterona foi maior em novilhas de corte mantidas nessa dieta. Contudo, as concentrações luteais de progesterona foram similares entre os grupos, o que indica que não houve diferença na taxa de secreção de progesterona. No entanto, o tempo requerido para a redução, pela metade, das concentrações circulantes de progesterona, após a ovariectomia, foi maior em novilhas alimentadas com dieta com suplementação de gordura. Dessa forma, os autores aventaram que o principal fator relacionado ao aumento das concentrações circulantes de progesterona, em vacas alimentadas com dieta rica em lipídios, seria a redução no metabolismo hepático dos esteroides.
Adicionalmente, Piccinato et al. (2010) observaram, in vitro, que ácidos graxos com cadeias de carbono de diferentes comprimentos diminuem o metabolismo de esteroides. Entretanto, esses resultados não foram corroborados pelo experimento realizado in vivo, com uso de infusão de óleo de linhaça no abomaso (Piccinato et al., 2010). Além disso, ainda não foi realizado um estudo preciso para calcular o fluxo sanguíneo hepático, nessas condições experimentais.

Em razão das diferenças na ingestão de matéria seca e no nível de produção de leite, os resultados de pesquisas com gado de leite não são necessariamente aplicáveis aos animais para produção de carne (Funston, 2004; Raes et al., 2004).

O objetivo do presente trabalho foi avaliar o efeito da suplementação de dieta com gordura protegida ruminal, no tamanho folicular, volume luteal e nas concentrações séricas de progesterona em novilhas Nelore.

\section{Material e Métodos}

$\mathrm{O}$ experimento foi realizado entre fevereiro e julho de 2008, na Estação Experimental da Embrapa Recursos Genéticos e Biotecnologia, em Brasília, DF (1552'S a $15^{\circ} 56$ ' $\mathrm{S}$ e $48^{\circ} 00^{\prime} \mathrm{W}$ a $48^{\circ} 02^{\prime} \mathrm{W}$, com altitudes entre 1.050 e $1.250 \mathrm{~m}$ ) (Walter \& Sampaio, 1998). Os protocolos de experimentação utilizados estavam de acordo com as regras do Comitê de Ética na Experimentação com Animais, da Universidade Estadual Paulista, e foram aprovados sob o número 19/2007-CEEA.

Quarenta novilhas da raça Nelore, não lactantes, com idade entre 24 e 36 meses, foram utilizadas em um experimento "crossover", com duas repetições e intervalo de 66 dias entre as datas de início de cada repetição. Todos os animais foram submetidos a avaliações ultrassonográficas ovarianas semanais, desde o início do experimento, para acompanhamento da ciclicidade (presença de CL em pelo menos uma de duas avaliações consecutivas). Estas avaliações ultrassonográficas foram realizadas por um único operador, com uso de um aparelho de ultrassom Aloka SSD-500 V, em tempo real (Aloka Co., Tóquio, Japão), com transdutor linear trans-retal de 7,5 MHz.

Ao início do experimento, os animais foram divididos, aleatoriamente, em dois grupos experimentais: $\mathrm{C}$, controle; e $\mathrm{G}$, alimentado com dieta suplementada com gordura protegida ruminal. Ambos 
os grupos foram mantidos em sistema de pastejo com Urochloa decumbens e água à vontade. Inicialmente, os animais dos grupos $\mathrm{C}$ e $\mathrm{G}$ apresentavam peso de $356,1 \pm 7,8$ e $361,7 \pm 7,4 \mathrm{~kg}$, e escore de condição corporal (ECC, escala de 1 a 5) (Houghton et al., 1990) de $2,86 \pm 0,03$ e 2,96 $\pm 0,05$, respectivamente. Além disso, na data de início da primeira repetição, havia oito e sete fêmeas em anestro, nos grupos $\mathrm{G}$ e $\mathrm{C}$, respectivamente. $\mathrm{Na}$ data de início da segunda repetição, sete e oito novilhas estavam anovulatórias nestes grupos experimentais.

Os suplementos foram oferecidos uma vez ao dia, em cochos coletivos cobertos, tendo-se usado a relação de $50 \mathrm{~cm}$ de cocho por animal, por 50 dias, em cada repetição. A segunda repetição foi iniciada 16 dias após a primeira, e os tratamentos foram invertidos. Os animais foram manejados em sistema de rodízio, em seis piquetes de 5 ha. Para que se eliminasse o efeito de piquete, a rotação dos animais foi realizada tendo-se o período de crescimento da forrageira como base. A taxa de lotação, em ambos os grupos experimentais, foi de 3,2 unidades animais por hectare (UA ha-1).

Os dois suplementos experimentais foram formulados para, associados à pastagem, atender aos requerimentos de mantença para novilhas em crescimento. $O$ suplemento recebido por $G$ foi formulado para fornecer $100 \mathrm{~g}$ de Megalac-E (Arm \& Hammer, Rio de Janeiro, Brasil) por cabeça por dia, de acordo com as recomendações do fabricante. Essa gordura protegida ruminal "bypass", derivada de óleo de soja, que possui predominância de ácido linoleico em sua composição, foi acrescida de $400 \mathrm{~g}$ de concentrado, no total de $500 \mathrm{~g}$. O suplemento para o grupo $\mathrm{C}$ foi formulado para fornecer $800 \mathrm{~g}$ de concentrado. Os suplementos foram calculados para serem oferecidos nessas proporções, a fim de torná-los isoenergéticos e isoproteicos. No entanto, na primeira repetição, observaram-se problemas no ajuste do consumo total diário do suplemento $\mathrm{G}$, que se manteve em $75,8 \%$, enquanto o consumo de $\mathrm{C}$ foi de $96,2 \%$ do esperado. Na segunda repetição do estudo, adicionaramse $100 \mathrm{~g}$ de milho moído por cabeça por dia, a cada um dos tratamentos, com o propósito de se elevar o consumo voluntário. Tal alteração resultou em um fornecimento diário de $900 \mathrm{~g}$ de concentrado por cabeça por dia, para o grupo C, e de $600 \mathrm{~g}$ concentrado por cabeça por dia para o $\mathrm{G}$.
Após a adição do milho moído, o consumo aumentou e manteve-se bem próximo do desejado, com $95,7 \%$ no grupo G e $98 \%$ no grupo C. Mesmo após a alteração, os suplementos continuaram isoenergéticos e isoproteicos, uma vez que foram mantidas as mesmas proporções para cada uma das dietas oferecidas, na primeira e segunda repetições. O consumo foi estimado por meio da pesagem diária da sobra do cocho.

A percentagem relativa dos ingredientes, utilizados para cada dieta experimental, encontra-se na Tabela 1.

Durante o experimento, foram realizadas avaliações semanais de ECC, e mensais do peso corporal dos animais, para monitoramento do efeito do suplemento com gordura protegida ruminal no estado físico das fêmeas.

Quinze dias após o início do fornecimento dos suplementos, todos os animais receberam um dispositivo intravaginal de liberação de progesterona CIDR, com 1,9 g de progesterona natural (Pfizer, Hamilton, Nova Zelândia) e uma aplicação i.m.

Tabela 1. Percentagem relativa dos ingredientes utilizados na composição dos suplementos experimentais com gordura protegida ruminal $(\mathrm{G})$ e controle $(\mathrm{C})$.

\begin{tabular}{lcc}
\hline Componentes & Grupo G (\%) & Grupo C (\%) \\
\hline Fosfato bicálcico & 12,5 & 7,8 \\
Carbonato de cálcio ${ }^{(1)}$ & 0,0 & 2,5 \\
Sulfato de cálcio & 1,0 & 0,6 \\
Flor de enxofre & 0,8 & 0,5 \\
Iodato de cálcio & 0,006 & 0,004 \\
Óxido de magnésio & 0,8 & 0,5 \\
Sulfato de zinco & 0,2 & 0,1 \\
Sulfato ferroso & 0,08 & 0,05 \\
Sulfato de manganês & 0,10 & 0,06 \\
Sulfato de cobre & 0,10 & 0,09 \\
Selenito de sódio & 0,002 & 0,001 \\
Sulfato de cobalto & 0,01 & 0,008 \\
Sal comum & 17,0 & 10,6 \\
Uramido 40 & 13,0 & 10,0 \\
Farelo de soja tostada & 15,0 & 0,0 \\
Agalmatolito & 4,0 & 5,1 \\
Milho & 15,3 & 62,0 \\
Vitamina A (1.000.000 UI g-1 $)$ & 0,003 & 0,002 \\
Vitamina E (500 UI g $\left.{ }^{-1}\right)$ & 0,010 & 0,008 \\
Vitamina D3 (500.000 UI g $\left.{ }^{-1}\right)$ & 0,004 & 0,003 \\
Megalac-E & 20,0 & 0,0 \\
\hline Total & 100,0 & 100,0 \\
\hline
\end{tabular}

${ }^{(1)}$ Componente não adicionado ao suplemento. 
de $25 \mathrm{mg}$ de PGF2 $\alpha$ utilizando Dinoprost Trometamina, Lutalyse (Pfizer, Paulínia, Brasil), com o propósito de proporcionar concentrações circulantes de progesterona, advindas exclusivamente do CIDR. Sete dias após a aplicação, o dispostivo intravaginal foi retirado e as novilhas receberam outra aplicação de PGF2 $\alpha$. Onze dias depois, uma nova aplicação de PGF2 $\alpha$ foi feita e, a partir de então, foram realizadas observações de estro, com duração de uma hora, quatro vezes ao dia (0h, 6h, 12h, 18h), e exames ultrassonográficos diários para acompanhamento do desenvolvimento folicular, até que a ovulação fosse confirmada. Além disso, foram obtidas mensurações ultrassonográficas do diâmentro do folículo pré-ovulatório e do volume luteal, 7 e 14 dias após a ovulação. O cálculo do volume luteal foi realizado conforme Sartori et al. (2002).

Colheitas de sangue foram realizadas pela punção da veia jugular, em tubos sem anticoagulante, nos seguintes períodos: quatro dias após a inserção do dispositivo intravaginal de progesterona, a fim de se detectar um possível efeito da gordura no metabolismo da progesterona; e 7 e 14 dias após a ovulação subsequente ao terceiro tratamento com PGF2 $\alpha$, para que se dosasse a concentração sérica de progesterona. Após a colheita, o sangue foi mantido por 4 horas à temperatura ambiente e, então, foi submetido à temperatura de $4^{\circ} \mathrm{C}$, por 24 horas. As amostras foram centrifugadas a $1.529 \mathrm{~g}$ por 15 min, para obtenção do soro. Em seguida, as amostras foram armazenadas a $-20^{\circ} \mathrm{C}$, para análise posterior.

A dosagem de progesterona foi realizada em duplicatas, por meio de radioimunoensaio ("coat-acount progesterone"), conforme indicação do fabricante, e obteve-se um coeficiente de variação intraensaio de $9,1 \%$. A sensibilidade do ensaio foi de $0,02 \mathrm{ng} \mathrm{mL}^{-1}$.

$\mathrm{Na}$ análise estatística, as variáveis peso corporal, ECC, tamanho do folículo ovulatório, volume luteal e concentrações séricas de progesterona aos 7 e 14 dias após ovulação foram analisadas por um modelo que incluiu efeito aleatório de novilha, tendo-se considerado a matriz de correlação autorregressiva de primeira ordem, por causa das medidas repetidas, assim como os efeitos fixos tratamento ( $\mathrm{G}$ e $\mathrm{C}$ ) e repetição (1 e 2), com o uso do procedimento mixed do SAS. Além disso, o efeito ciclicidade dentro de período foi incluído no modelo para a variável concentração sérica de progesterona, aos quatro dias após a inserção do dispositivo intravaginal de progesterona.

\section{Resultados e Discussão}

Apesar de os animais terem ganhado peso durante o experimento, não houve diferença entre os tratamentos em relação ao peso e ECC médios das novilhas, durante todo o período experimental. Tal resultado era esperado, pois os animais dos dois grupos experimentais receberam dieta em quantidades ajustadas para serem isoenergéticas e isoproteicas.

Com relação à avaliação indireta da influência da suplementação com gordura protegida ruminal no metabolismo de hormônios esteroides, foi detectada diferença $(p=0,008)$ nas concentrações séricas de progesterona, aos quatro dias após a inserção do dispositivo intravaginal e aplicação de PGF2 $\alpha$, entre os grupos $\mathrm{G}$ $\left(3,8 \pm 0,3 \mathrm{ng} \mathrm{mL}^{-1} ; \mathrm{n}=24\right)$ e $\mathrm{C}\left(2,8 \pm 0,3 \mathrm{ng} \mathrm{mL}^{-1} ; \mathrm{n}=25\right)$.

Embora tenham sido realizados 80 protocolos de sincronização com PGF2 $\alpha$, a taxa de detecção de estro foi de 30\% (12 em 40), no grupo G, e de $22,5 \%$ (9 em $40)$, no grupo $\mathrm{C}$, enquanto a taxa de ovulação representou 45\% (18 em 40) e 50\% (20 em 40), nos respectivos grupos experimentais, e todas as novilhas que manifestaram estro ovularam. As baixas taxas de detecção de estro podem ter sido decorrentes de diversos fatores, como o insucesso em se induzir ciclicidade nas novilhas pré-púberes, com o uso do dispositivo intravaginal de progesterona novo, ao qual esta categoria animal é mais sensível, em razão da diminuição da pulsatilidade do LH provocada pela progesterona. Assim, era de se esperar que pelo menos 30 dos 80 animais submetidos ao protocolo de sincronização não apresentassem resposta satisfatória. Outros estudos com a raça Nelore também obtiveram baixos índices de detecção de estro após sincronização (Figueiredo et al., 1997; Pinheiro et al., 1998). Adicionalmente, deve-se considerar que as novilhas foram submetidas a um manejo intensivo para avaliações ultrassonográficas e colheitas sanguíneas, e que tais fontes de estresse podem ter influenciado negativamente a expressão de estro e subsequente ovulação (Dobson et al., 2001).

O tamanho do folículo ovulatório e o volume luteal, 7 e 14 dias após a ovulação, não diferiram entre os grupos $\mathrm{G}$ e C (Tabela 2). Não obstante, outros estudos detectaram aumento do diâmetro do folículo dominante, em vacas de leite que receberam dieta rica em AGP (Robinson et al., 2002). Da mesma forma, maior folículo pré-ovulatório foi relatado em vacas de leite que receberam ácido linolênico (Ambrose et al., 2006; 
Bilby et al., 2006) e linoleico (Bilby et al., 2006). Uma das razões para a ausência de efeito da suplementação com gordura nessas variáveis reprodutivas, no presente estudo, pode ter sido o fornecimento insuficiente de Megalac-E para as novilhas (100 $\left.\mathrm{g} \mathrm{dia}^{-1}\right)$, apesar de esta quantidade ser a sugerida pelos fabricantes e utilizada em experimentos que obtiveram resultados positivos na fertilidade.

Em estudos recentes, observou-se que a dieta com suplementação rica em ácido linoleico ou linolênico não altera o tamanho do folículo dominante (Ambrose et al., 2006), o diâmetro e a taxa de crescimento do folículo pré-ovulatório (Childs et al., 2008b), o tamanho do CL e a concentração plasmática de progesterona (Ambrose et al., 2006; Childs et al., 2008b). Vacas leiteiras alimentadas com sais de cálcio de ácido graxo linoleico também apresentaram diâmetros similares do folículo pré-ovulatório e luteal, em comparação aos animais que receberam sais de cálcio de óleo de palma (Cerri et al., 2009). Da mesma forma, os suplementos lipídicos, enriquecidos com ácidos graxos n-9 cis (18:1c, oleico), n-9 trans (18:1t), n-6 (18:2, linoleico, Megalac-R) ou n-3 (18:3, linolênico), não interferiram nas concentrações circulantes de progesterona (Bilby et al., 2006).

Com relação ao metabolismo da progesterona, resultados similares aos do presente estudo foram observados em vacas mestiças não lactantes e ovariectomizadas, cujas concentrações plasmáticas de progesterona foram menores em animais que não receberam esta gordura na dieta $\left(1,65 \mathrm{vs} .1,81 \mathrm{ng} \mathrm{mL}^{-1}\right.$; $\mathrm{p}<0,01$ ) (Lopes et al., 2009). Tais resultados podem ser decorrentes da maior produção deste esteróide ou de seu menor metabolismo hepático.

A maioria dos trabalhos corrobora esta última hipótese, apesar de ainda não se ter avaliado diretamente o fluxo hepático de animais alimentados nestas condições dietéticas. Esta pode ser uma possível via de ação em que os AGP proporcionam efeito positivo na fertilidade de fêmeas bovinas. Associado a estes resultados, maiores taxas de prenhez, encontradas em animais que consumiram dietas suplementadas com ácido linoleico, após inseminação artificial (IA) e inovulação de embriões, reforçam a hipótese de atuação dos AGP no útero, pelo auxílio em mecanismos antiluteolíticos. A infusão de gordura com alta quantidade de ácido linoleico no abomaso (Oldick et al., 1997) ou a suplementação com AGP n-6 protegido (Cheng et al., 2001) provocaram menor liberação de PGF $2 \alpha$, em resposta à ocitocina. Lopes et al. (2009) forneceram Megalac-E durante o início do protocolo de sincronização do estro até 28 dias após a inseminação artificial a tempo fixo (IATF), em vacas Nelore lactantes, e observaram taxas de prenhez superiores $(51,2 \%, \mathrm{n}=451)$ às do grupo que não recebeu suplementação $(39,6 \%, n=459 ; \mathrm{p}=0,04)$. Peres et al. (2008) forneceram dieta com semente de girassol, rica em AGP linoleico, a vacas Nelore pós-parto $(n=133)$, do momento da IA até 22 dias, e observaram aumento de $20,4 \%$ na taxa de concepção das vacas que receberam esta dieta.

Ao adicionar Megalac-E à suplementação mineral proteica de receptoras de embrião mestiças $(n=435)$, do final do protocolo de sincronização até 21 dias após a transferência dos embriões, Lopes et al. (2009) observaram acréscimo na taxa de concepção de $11,9 \%$, em relação ao grupo controle. Esses autores verificaram que os AGP possuem efeito pós IA ou transferência de embrião, provavelmente durante $\mathrm{o}$ período de luteólise.

Um dos mecanismos de ação dos AGP na fertilidade se dá por meio do aumento das concentrações plasmáticas de progesterona que, provavelmente, inibe a resposta luteolítica e contribui para a manutenção da prenhez (Petit \& Twagiramungu, 2006; Childs et al., 2008a). Outras possibilidades estão relacionadas à

Tabela 2. Média \pm EP dos quadrados mínimos do tamanho do folículo ovulatório, volume luteal e concentração sérica de progesterona, aos 7 e 14 dias após a ovulação, em novilhas Nelore alimentadas com dieta suplementada com gordura protegida ruminal $(\mathrm{G})$ ou sem a adição de gordura protegida $(\mathrm{C})$.

\begin{tabular}{lcc}
\hline Variável & Grupo $\mathrm{G}(\mathrm{n}=18)$ & Grupo C $(\mathrm{n}=20)$ \\
\hline Folículo ovulatório $(\mathrm{mm})$ & $12,5 \pm 0,3$ & $12,3 \pm 0,3$ \\
Volume luteal, 7 dias após ovulação $\left(\mathrm{mm}^{3}\right)$ & $2.270,2 \pm 312,8$ & $2.356,1 \pm 300,5$ \\
Progesterona sérica, 7 dias após ovulação $\left(\mathrm{ng} \mathrm{mL}^{-1}\right)$ & $3,4 \pm 0,3$ & $3,4 \pm 0,2$ \\
Volume luteal, 14 dias após ovulação $\left(\mathrm{mm}^{3}\right)$ & $2.861,6 \pm 223,1$ & 0,80 \\
Progesterona sérica, 14 dias após ovulação $\left(\mathrm{ng} \mathrm{mL}^{-1}\right)$ & $6,9 \pm 0,4$ & $2.627,3 \pm 215,2$ \\
\hline
\end{tabular}

Pesq. agropec. bras., Brasília, v.45, n.4, p.408-414, abr. 2010 
alteração da expressão gênica uterina e embrionária ou ao efeito direto no embrião. Assim, estudos que avaliem o efeito da suplementação de gordura protegida sobre a qualidade embrionária, na expressão gênica embrionária e uterina e no desenvolvimento embrionário in vivo, são necessários para uma maior compreensão do conjunto de ação desse ingrediente na nutrição de zebuínos.

\section{Conclusões}

1. O consumo de gordura protegida ruminal, na dose de $100 \mathrm{~g} \mathrm{dia}^{-1}$ de Megalac-E, afeta as concentrações circulantes de progesterona, provavelmente pela diminuição do metabolismo hepático dos esteroides, em fêmeas zebuínas em pasto.

2. A suplementação com Megalac-E, na dosagem utilizada, não altera o tamanho do folículo ovulatório e o volume luteal, em novilhas Nelore.

\section{Agradecimentos}

À Fundação de Amparo à Pesquisa do Estado de São Paulo, pela concessão de bolsa de estudos; e às empresas Arm \& Hammer, Integral Nutrição Animal e Pfizer Saúde Animal, pela doação dos produtos para realização do experimento.

\section{Referências}

AMBROSE, D.J.; KASTELIC, J.P.; CORBETT, R.; PITNEY, P.A.; PETIT, H.V.; SMALL, J.A.; ZALKOVIC, P. Lower pregnancy losses in lactating dairy cows fed a diet enriched in $\alpha$-linolenic acid. Journal of Dairy Science, v.89, p.3066-3074, 2006.

BILBY, T.R.; BLOCK, J.; AMARAL, B.C. do; SA FILHO, O.; SILVESTRE, F.T.; HANSEN, P.J.; STAPLES, C.R.; THATCHER, W.W. Effects of dietary unsaturated fatty acids on oocyte quality and follicular development in lactating dairy cows in summer. Journal of Dairy Science, v.89, p.3891-3903, 2006.

CERRI, R.L.A.; JUCHEM, S.O.; CHEBEL, R.C.; RUTIGLIANO, H.; BRUNO, R.G.S.; GALVÃO, K.N.; THATCHER, W.W.; SANTOS, J.E.P. Effect of fat source differing in fatty acid profile on metabolic parameters, fertilization, and embryo quality in highproducing dairy cows. Journal of Dairy Science, v.92, p.15201531, 2009.

CHENG, Z.; ROBINSON, R.S.; PUSHPAKUMARA, P.G.A.; MANSBRIDGE, R.J.; WATHES, D.C. Effect of dietary polyunsaturated fatty acids on uterine prostaglandin synthesis in the cow. Journal of Endocrinology, v.171, p.463-473, 2001.

CHILDS, S.; CARTER, F.; LYNCH, C.O.; SREENAN, J.M.; LONERGAN, P.; HENNESSY, A.A.; KENNY, D.A. Embryo yield and quality following dietary supplementation of beef heifers with n-3 polyunsaturated fatty acids (PUFA). Theriogenology, v.70, p.992-1003, 2008a.

CHILDS, S.; LYNCH, C.O.; HENNESSY, A.A.; STANTON, C.; WATHES, D.C.; SREENAN, J.M.; DISKIN, M.G.; KENNY, D.A. Effect of dietary enrichment with either n-3 or n- 6 fatty acids on systemic metabolite and hormone concentration and ovarian function in heifers. Animal, v.2, p.883-893, 2008b.

DOBSON, H.; TEBBLE, J.E.; SMITH, R.F.; WARD, W.R. Is stress really all that important? Theriogenology, v.55, p.65-73, 2001.

FIGUEIREDO, R.A.; BARROS, C.M.; PINHEIRO, O.L.; SOLER, J.M. Ovarian follicular dynamics in Nelore breed (Bos indicus) cattle. Theriogenology, v.47, p.1489-1505, 1997.

FUNSTON, R.N. Fat supplementation and reproduction in beef females. Journal of Animal Science, v.82, p.154-161, 2004.

HAWKINS, D.E.; NISWENDER, K.D.; OSS, G.M.; MOELLER, C.L.; ODDET, K.G.; SAWYER, H.R.; NISWENDER, G.D. An increase in serum lipids increases luteal lipid content and alters the disappearance rate of progesterone in cows. Journal of Animal Science, v.73, p. 541-545, 1995.

HIGHTSHOE, R.B.; COCHRAN, R.C.; CORAH, L.R.; KIRACOFE, G.H.; HARMON, D.L.; PERRY, R.C. Effects of calcium soaps of fatty acids on postpartum reproductive function in beef cows. Journal of Animal Science, v.69, p.4097-4103, 1991.

HOUGHTON, P.L.; LEMENAGER, R.P.; HENDRIX, K.S.; MOSS, G.E.; STEWART, T.S. Effects of body composition, preand postpartum energy intake and stage of production of energy utilization by beef cows. Journal of Animal Science, v.68, p.14471456, 1990.

KIM, J.Y.; KINOSHITA, M.; OHNISHI, M.; FUKUI, Y. Lipid and fatty acid analysis of fresh and frozen-thawed immature and in vitro matured bovine oocytes. Reproduction, v.122, p.131-138, 2001.

KOJIMA, T.; ZENIYA, Y.; AOYAMA, T.; KONDO, A.; YOSHINO, J. Dietary administration of fatty acids-enriched mold dried cell containing $\gamma$-linolenic acid to female pigs improves ovulation rate and embryo quality in summer. Journal of Reproduction and Development, v.43, p.121-127, 1997.

LOPES, C.N.; SCARPA, A.B.; CAPPELLOZZA, B.I.; COOKE, R.F.; VASCONCELOS, J.L.M. Effects of rumen-protected polyunsaturated fatty acid supplementation on reproductive performance of Bos indicus beef cows. Journal of Animal Science, v.87, p.3935-3943, 2009.

LUCY, M.C.; STAPLES, C.R.; MICHEL, F.M.; THATCHER, W.W. Effect of feeding calcium soaps to early postpartum dairy cows on plasma prostaglandin F2 $\alpha$, luteinizing hormone, and follicular growth. Journal of Dairy Science, v.74, p.483-489, 1991.

OLDICK, B.S.; STAPLES, C.R.; THATCHER, W.W.; GYAWU, P. Abomasal infusion of glucose and fat: effect on digestion, production, and ovarian and uterine functions of cows. Journal of Dairy Science, v.80, p.1315-1328, 1997.

PETIT, H.V.; DEWHURST, R.J.; SCOLLAN, N.D.; PROULX, J.G.; KHALID, M.; HARESIGN, W.; TWAGIRAMUNGU, H.; MANN, G.E. Milk production and composition, ovarian function, 
and prostaglandin secretion of dairy cows fed omega-3 fats. Journal of Dairy Science, v.85, p.889-899, 2002.

PETIT, H.V.; TWAGIRAMUNGU, H. Conception rate and reproductive function of dairy cows fed different fat sources. Theriogenology, v.66, p.1316-1324, 2006.

PICCINATO, C.A.; SARTORI, R.; SANGSRITAVONG, S.; SOUZA, A.H.; GRUMMER, R.R.; LUCHINI, D.; WILTBANK, M.C. In vitro and in vivo analysis of fatty acid effects on metabolism of $17 \beta$-estradiol and progesterone in dairy cows. Journal of Dairy Science, v.93, p.1934-1943, 2010.

PINHEIRO, O.L.; BARROS, C.M.; FIGUEIREDO, R.A.; VALLE, E.R. do; ENCARNAÇÃO, R.O.; PADOVANI, C.R. Estrous behavior and the estrus-to-ovulation interval in Nelore cattle (Bos indicus) with natural estrus or estrus induced with prostaglandin F2 alpha or norgestomet and estradiol valerate. Theriogenology, v.49, p.667-681, 1998.

RAES, K.; DE SMET, S.; DEMEYER, D. Effect of dietary fatty acids on incorporation of long chain polyunsaturated fatty acids and conjugated linoleic acid in lamb, beef and pork meat: a review. Animal Feed Science and Technology, v.113, p.199-221, 2004.

ROBINSON, R.S.; PUSHPAKUMARA P.G.A.; CHENG, Z.; PETERS, A.R.; ABAYASEKARA, D.R.E.; WATHES, D.C. Effects of dietary polyunsaturated fatty acids on ovarian and uterine function in lactating dairy cows. Reproduction, v.124, p.119-131, 2002.

RYAN, D.P.; SPOON, R.A.; WILLIAMS, G.L. Ovarian follicular characteristics, embryo recovery, and embryo viability in heifers fed high-fat diets and treated with follicle-stimulation hormone. Journal of Animal Science, v.70, p.3505-3513, 1992.

SARTORI, R.; ROSA, G.J.M.; WILTBANK, M.C. Ovarian structures and circulating steroids in heifers and lactating cows in summer and lactating and dry cows in winter. Journal of Dairy Science, v.85, p.2813-2822, 2002.

THOMAS, M.G.; BAO, B.; WILLIAM, G.L. Dietary fats varying in their fatty acid composition differentially influence follicular growth in cows fed isoenergetic diets. Journal of Animal Science, v.75, p.2512-2519, 1997.

WALTER, B.M.T.; SAMPAIO, A.B. A vegetação da fazenda Sucupira. Brasília: Embrapa Recursos Genéticos e Biotecnologia, 1998. 110p.

ZERON, Y.; SKLAN, D.; ARAV, A. Effect of polyunsaturated fatty acid supplementation on biophysical parameters and chilling sensitivity of ewe oocytes. Molecular Reproduction and Development, v.61, p.271-278, 2002.

Recebido em 18 de maio de 2009 e aprovado em 18 de março de 2010 